\title{
Giving voice to food insecurity in a remote indigenous community in subarctic Ontario, Canada: traditional ways, ways to cope, ways forward
}

Kelly Skinner ${ }^{1 *}$, Rhona M Hanning ${ }^{1}$, Ellen Desjardins ${ }^{2}$ and Leonard JS Tsuji ${ }^{1,3}$

\begin{abstract}
Background: Food insecurity is a serious public health issue for Aboriginal people (First Nations [FN], Métis, and Inuit) living in Canada. Food security challenges faced by FN people are unique, especially for those living in remote and isolated communities. Conceptualizations of food insecurity by FN people are poorly understood. The purpose of this study was to explore the perceptions of food insecurity by FN adults living in a remote, on-reserve community in northern Ontario known to have a high prevalence of moderate to severe food insecurity.
\end{abstract}

Methods: A trained community research assistant conducted semi-directed interviews, and one adult from each household in the community was invited to participate. Questions addressed traditional food, coping strategies, and suggestions to improve community food security and were informed by the literature and a community advisory committee. Thematic data analyses were carried out and followed an inductive, data-driven approach.

Results: Fifty-one individuals participated, representing $67 \%$ of eligible households. The thematic analysis revealed that food sharing, especially with family, was regarded as one of the most significant ways to adapt to food shortages. The majority of participants reported consuming traditional food (wild meats) and suggested that hunting, preserving and storing traditional food has remained very important. However, numerous barriers to traditional food acquisition were mentioned. Other coping strategies included dietary change, rationing and changing food purchasing patterns. In order to improve access to healthy foods, improving income and food affordability, building community capacity and engagement, and community-level initiatives were suggested.

Conclusions: Findings point to the continued importance of traditional food acquisition and food sharing, as well as community solutions for food systems change. These data highlight that traditional and store-bought food are both part of the strategies and solutions participants suggested for coping with food insecurity. Public health policies to improve food security for FN populations are urgently needed.

Keywords: Canada, First Nations, Food security, Nutrition policy, Poverty, Remote, Coping strategies

\footnotetext{
* Correspondence: kskinner@uwaterloo.ca

${ }^{1}$ School of Public Health and Health Systems, University of Waterloo, 200

University Avenue West, Waterloo, ON N2L 3G1, Canada

Full list of author information is available at the end of the article
} 


\section{Background}

Food insecurity is a serious public health issue for Canada's indigenous population [1,2]. The term "Aboriginal people" describes the three groups that comprise Canada's indigenous population; First Nations [FN], Métis, and Inuit. First Nations are the largest of these three groups, making up nearly $60 \%$ of the Aboriginal population living in Canada with approximately $60 \%$ of FN people living off-reserve lands. Data on food security in off-reserve Aboriginal people are alarming; $24 \%$ of Aboriginal households had a compromised diet (reduced quality and/or quantity), and $33 \%$ experienced food insecurity compared to $8.4 \%$ and 9\%, respectively across the rest of Canada [3-5]. In onreserve FN households and Inuit households in Arctic communities the prevalence of food insecurity appears to be even higher. The First Nations Regional Health Survey found just over half (54.2\%) of households surveyed were food insecure, while the Inuit Health Survey conducted in 36 Arctic communities found a range of household food insecurity from 45-69\% depending on region [6,7]. Food insecurity in Aboriginal households in Canada has been associated with high levels of poverty, multi-child households, low levels of education attainment and labour force participation, reliance on social assistance/welfare, and female lone-parent households [5].

Food security challenges faced by Aboriginal people are unique [1,8-12], especially for Aboriginal people living in remote and isolated communities. Aboriginal food systems are primarily characterized by two avenues of food provision: the harvesting, sharing and consumption of traditional (or country) foods and the purchasing and consumption of market (or commercial or store-bought) foods [11,12]. Food harvested from the wild by FN people is called "traditional food" while the Inuit call wild-harvested food "country food". Despite the combination of the traditional food system and market food system as being distinct from the non-Aboriginal food system, current conceptualizations of food security lack the context, food practices, and perspectives of Aboriginal people [1].

Regardless of evidence that food insecurity is prevalent in Aboriginal communities, little information is known about the characteristics of the individuals or households experiencing this problem [13]. While numerous food system studies have been published on Inuit people living in the Canadian Arctic in recent years [7,14-23], there are still few food system studies with on-reserve FN communities [12]. Many gaps remain about the nature and extent of food insecurity for FN people in Canada. Lead authors in this field $[1,2,5]$ have recommended qualitative studies to better understand the food security situation for FN people. The knowledge gained can help to tailor food security programs and policies to the unique needs of these communities and population $[1,5]$.
In this study, we explored food insecurity from the perspective of FN adults living in a remote, on-reserve subarctic community in northern Ontario, Canada. Previous work by our group had identified a high prevalence of household food insecurity (70\%) using the Household Food Security Survey Module [4,24]. The intention of this study was to determine participants' perceptions of food security and the range of adaptive strategies they use at an individual and household level. The two research questions addressed by this study were: (1) "What are the coping strategies for food insecurity used by community members?"; and, (2) "What suggestions do they have to improve food security in their community?"

\section{Community profile and study population}

This study was conducted in Fort Albany First Nation which is situated on the west coast of James Bay in the Mushkegowuk Territory along the Albany River in northern Ontario, Canada. As described previously [25,26], the Fort Albany reserve is home to approximately 850 people. Fort Albany is geographically remote $\left(52^{\circ} 15^{\prime} \mathrm{N} ; 81^{\circ} 35^{\prime}\right.$ W); it is accessible only by plane year-round, by boat and barge during the ice-free season, and by ice road after freeze-up. In Canada, a remote community is defined as being more than 350 kilometres from the nearest service centre (or city) having year-round road access. Fort Albany also is categorized as a community with "special access" which means that it is located in a zone where there is no year-round road access to a service centre. Timmins, Ontario is 769 kilometres from Fort Albany and is one of the closest cities with road access. Timmins is considered a main entry point for food distribution to Fort Albany as food is flown from there during most of the year with the exception of 6-8 weeks in the winter when the ice road allows for accessibility to closer communities. One of the communities accessible by ice road is Moosonee, which is 128 kilometres southeast of Fort Albany and has train access. As a result of being remote with special access, transportation of goods into the community of Fort Albany, including commercial food, is very expensive.

At the time of this study, the community had one main grocery store and two small convenience stores. Although traditional foods remain an important part of their diet, the majority of dietary intake is from store bought food. Community members participate in traditional harvesting activities (also referred to as traditional food acquisition) including hunting, fishing, and gathering food from the land. However, these activities have been declining in recent decades, especially for young people. As these endeavours are seasonal, are limited by financial constraints for harvesting transportation and equipment, and the yield varies greatly depending on the success of the harvest, there is much variability in the 
consumption of traditional foods between households and over the course of the year. Traditional foods commonly harvested and consumed include berries (e.g., ground berries - Gaultheria procumbens), fish (e.g., whitefish - Coregonus clupeaformis), large land-based animals (e.g., moose - Alces alces), game birds (e.g., goose - Branta canadensis interior and Anser caerulescens caerulescens), and small game (e.g., hare - Lepus americanus). Community members live in small houses and many households have extended family living together.

Fort Albany First Nation was an ideal location for this project for a number of reasons: we have established a community advisory committee with broad community representation; have good rapport with the community and school as we have been working on school programs for healthy eating and physical activity for many years; and community members have a keen interest in improving the dietary habits of their population [25-28].

\section{Methods}

This study builds upon our previous work where community focus groups and individual interviews with Fort Albany community members identified food insecurity as a constraint to healthy eating in children and youth $[25,27]$. This study was also part of a larger project to examine food security in the community. The theoretical framework for the larger project was based on systems thinking and a critical social theory perspective [29]. Critical social theory includes aspects of theories from feminism, postcolonialism, and Indigenist critical theory which better reflects Indigenous ways of knowing than a purely postcolonial approach [29]. This theory allows for a more holistic spiritual viewpoint and represents an Indigenous research paradigm that supports self-determination. The theory also focuses on specific language used by participants as a source of information about meaning [29].

\section{Community advisory committee}

A community advisory committee (CAC) of six community members representing local stakeholder organizations (e.g., Band Council, Health Centre, school) and parents and the community at large was established prior to the study. For this study, members of the CAC were involved in the design of data collection tools (e.g., qualitative questions and probes), helped to adapt approaches to decrease the cultural sensitivity of study methodologies, assisted in collecting data, provided input on the interpretation of results, and assisted with the dissemination of results. Although a trusting relationship between the investigators and members/organizations in the community has been previously established, the specific formation of a CAC was fundamental to this participatory research. Ethics approval for this study was obtained from the Office of Research Ethics at the University of Waterloo and permission to conduct this study was obtained from Fort Albany First Nation.

\section{Question development}

As part of the larger project, the first part of each interview began with having the participants respond to the 18-item US Household Food Security Survey Module (HFSSM). The HFSSM is a government questionnaire that was used by Health Canada in the 2004 Canadian Community Health Survey (Cycle 2.2) to determine the prevalence and severity of food insecurity in the offreserve population [4]. The qualitative interviews for the current study were conducted following completion of the HFSSM, which is why the first interview question refers to the government questionnaire.

Lambden and colleagues [30] concluded that traditional food attributes must be included in studies of food security in the Arctic. Although this study was in the subarctic, it is apparent from previous work with Cree in the western James Bay region that questions related to traditional food are very important for studying food security in this community. These considerations were taken into account during the question development for the qualitative interviews.

A set of three questions and probes were developed using an iterative process: 1) Initially, nine questions were informed by the qualitative food security literature, including studies with Aboriginal populations in Canada (e.g., [15,22,31]); 2) During subsequent drafts, questions were reviewed to ensure they were more understandable, culturally appropriate and relevant to the food security issues in FN communities based on consultation with and input from members of the CAC $(n=3)$ and the investigators' $(n=3)$ personal experiences with the people and community of Fort Albany. The number of questions for the final draft $(n=3)$ was kept small to reduce the response burden for the participants. The final three questions were: (1) The government questionnaire we did seemed to ask mostly about store-bought foods. Can you tell me about traditional foods and your household?, (2) How do you adapt if there doesn't seem to be enough food (traditional or store-bought) for your household?, and (3) What do you think can be done to make it easier for people in Fort Albany to get enough (healthy) food (store-bought and/or traditional food)?. Table 1 displays the final three questions and probes.

\section{Participant recruitment, consent, and data collection}

A local community research assistant was hired to collect the data. He had been employed by our research team in the past and trained in proper protocols for data collection, including the administration of surveys and conducting interviews. He had an understanding of the project's aims, was instructed to provide probes when appropriate, and was familiar with the practice of active 
Table 1 Interview questions and probes

\begin{tabular}{|c|c|}
\hline Questions & Probes \\
\hline \multirow{4}{*}{$\begin{array}{l}\text { Q1. The government questionnaire we did seemed to ask mostly about store- } \\
\text { bought foods. Can you tell me about traditional foods and your household? }\end{array}$} & Probe for \\
\hline & - Any barriers to accessing traditional food \\
\hline & - Has environmental change affected access to traditional foods \\
\hline & - Any methods to increase traditional food access and consumption \\
\hline \multirow{2}{*}{$\begin{array}{l}\text { Q2. How do you adapt if there doesn't seem to be enough food } \\
\text { (traditional or store-bought) for your household? }\end{array}$} & Probe for \\
\hline & - e.g., things you might do to make food last longer, other sources of food \\
\hline \multirow{3}{*}{$\begin{array}{l}\text { Q3. What do you think can be done to make it easier for people in Fort } \\
\text { Albany to get enough (healthy) food (store-bought and/or traditional food)? }\end{array}$} & Probe for \\
\hline & $\begin{array}{l}\text { - Community (community), band (government), band council } \\
\text { (government), school (community, individual), people (individual) }\end{array}$ \\
\hline & - Food sharing between community members and families \\
\hline
\end{tabular}

listening during interviews [32]. The community assistant spoke Cree, which was helpful if any of the participants requested Cree translation. The assistant was also a member of Fort Albany First Nation, had stature in the community, and has lived there for more than 25 years. Therefore, the assistant had full understanding of the language and culture of the respondents as well as established trust and rapport; all of which are important elements for conducting qualitative interviews [33]. The status of the interviewer was very important for the comfort of the participants in discussing the sensitive topics around food insecurity.

One adult in each of the on-reserve FN homes in Fort Albany was approached in-person by the community research assistant to participate in the study. Participants were provided with an information/recruitment letter and/ or the study was explained orally. Participants were given the option to be interviewed in their language of choice and their location of choice. As in our previous studies, verbal consent was obtained from all participants, being culturally appropriate for the Western James Bay region for this type of project $[27,34]$. Semi-directed, in-depth interviews were conducted with each willing participant from June 2009 to January 2011. Interviews were guided by the three open-ended questions and the probes were only used to prompt more discussion if the participant needed examples to stimulate the conversation. The CAC decided that due to the sensitive nature of the topic of food insecurity it was not appropriate to audio-record the interviews. The community research assistant took verbatim handwritten notes during interviews. Demographic characteristics of the respondent and household were also collected. Interviews were coded by number for anonymity and to maintain confidentiality of respondents. All willing respondents participated in the interview regardless of whether their household was classified as food secure or food insecure.

The university research team was in regular contact with the community assistant either in-person or by telephone to discuss progress on data collection and to answer any questions that might come up related to the data collection. Interview transcripts were periodically returned to the research team in batches as they were completed.

\section{Data management and analysis}

The handwritten interviews were transcribed verbatim. Organization and coding of the transcribed data for the qualitative analysis was conducted both by hand and using QSR NVivo ${ }^{\circledR}$ computer software (NVivo, version 8.0; Doncaster, Australia: Sage Publications Software, 2008). Thematic data analyses were carried out according to the stages and steps described by Boyatzis [35] and followed an inductive, data-driven approach [35]. Initially, the raw data were reduced into logical and meaningful segments on paper [36]. Subsequently, data were organized into groups, and "themes" [37] were identified within a subsample of data from ten randomly selected interviews. The themes were then compared across subsamples and codes were created. Creating the codes was an iterative process of the writing, editing, and reconstruction of statements from the preliminary themes into a set of revised themes using the qualitative techniques of the constant comparison method and searching for deviant cases [38]. The qualitative analysis continued until saturation was reached, where no new themes emerged from the data. This also was an indication that there were a sufficient number of interviews and the sample size was adequate [39]. During the process of analyses, the theme and subtheme labels were created based on an interpretation of the statements and phrases of the participants. Therefore, the thematic labels presented in the study findings are not a verbatim representation of the exact words spoken by the participants during the interviews. Memos were used to record thoughts and ideas about the codes during the process of code development [40]. The codes were then used to analyse the rest of the qualitative data from all of the interviews. Initially the three interview questions were coded separately. Then the analysis was opened and coded across 
the three questions as the analyst found that the questions asked "triangulated". The final codes were arranged into a hierarchical coding list.

Initial thematic analysis was conducted by the lead author. To determine the consistency of judgment of the coders and to establish inter-rater reliability [41,42], the codes for the themes and subthemes were confirmed by a second independent analyst who had documented expertise with qualitative methods and analysis and expertise on the topic of food security [43,44]. The second analyst applied the themes to a subset of the data which was a random selection of $50 \%(n=25)$ of the interviews. The percent agreement between the two coders was $83 \%$. The second coder also recommended the reorganization and addition of two subthemes and one main theme. The additions of these themes were discussed between the two coders and it was agreed that they should be included in the analysis. The final code included 10 themes and 39 subthemes.

Final emergent themes and subthemes were shared with a few of the interviewed participants $(n=5)$ by the lead author to confirm that they accurately reflected their perspectives. A listing of the themes and subthemes was discussed with members of the CAC and revisions to the wording of the final themes and subthemes were suggested. Sharing the themes with participants and the CAC was a form of member checking to verify results of the study [45].

\section{Results}

Of the 76 individuals approached to participate in this study, 10 declined participation in the larger study, and 15 refused to participate in the interviews, resulting in a response rate of $67 \%$. A total of 51 respondents participated in the interviews, 27 male and 24 female with an average age of 43.7 years. The main reason 15 individuals chose not to participate in the interviews was respondent fatigue as they had already completed the HFSSM questionnaire. Just over half of the nonparticipants were male $(\mathrm{n}=8,53 \%)$ and lived in households categorized as food secure $(n=8,53 \%)$ and their average age was 41.3 years. Personal and household characteristics of the participating study population are shown in Table 2. Although more than three-quarters of the 51 participants had a salary from employment as their main source of income, $75.5 \%$ lived in households that were classified by the HFSSM as food insecure.

The results section documents an interpretation of the findings based on the three interview questions that were asked and selected discussions that followed between participants and interviewer. Figure 1 illustrates the hierarchical coding list of themes and subthemes that represent the participant's perspectives on food insecurity. Although there was some overlap between the questions asked, the interviews generally
Table 2 Personal and household characteristics of participants $(n=51)$

\begin{tabular}{|c|c|c|}
\hline & $\mathbf{N}$ & $\%$ \\
\hline \multicolumn{3}{|l|}{ Personal characteristics of participants } \\
\hline \multicolumn{3}{|l|}{ Age in years } \\
\hline $21-30$ & 3 & 5.9 \\
\hline $31-40$ & 16 & 31.4 \\
\hline $41-50$ & 22 & 43.1 \\
\hline $51-60$ & 10 & 19.6 \\
\hline \multicolumn{3}{|l|}{ Sex } \\
\hline Male & 27 & 52.9 \\
\hline Female & 24 & 47.1 \\
\hline \multicolumn{3}{|l|}{ Highest level of education } \\
\hline Elementary graduate or less & 17 & 33.3 \\
\hline Secondary graduate or some secondary & 19 & 37.3 \\
\hline Post-secondary graduate or some post-secondary & 15 & 29.4 \\
\hline \multicolumn{3}{|l|}{ Main source of income } \\
\hline Salary/wages from employment & 39 & 76.5 \\
\hline Social assistance or other ${ }^{a}$ & 12 & 23.5 \\
\hline \multicolumn{3}{|l|}{ Household characteristics of participants } \\
\hline \multicolumn{3}{|l|}{ Household food insecurity ${ }^{b}$} \\
\hline Food secure household & 12 & 24.5 \\
\hline Moderately food insecure household & 27 & 55.0 \\
\hline Severely food insecure household & 10 & 20.5 \\
\hline \multicolumn{3}{|l|}{ Household type } \\
\hline Couple with children & 31 & 60.8 \\
\hline Couple, no children ${ }^{c}$ & 11 & 21.6 \\
\hline Lone parent $^{d}$ & 7 & 13.7 \\
\hline Other $^{e}$ & 2 & 3.9 \\
\hline \multicolumn{3}{|l|}{ Children $<18$ years living in household } \\
\hline None & 13 & 25.5 \\
\hline 1 or 2 & 25 & 49.0 \\
\hline $3+$ & 13 & 25.5 \\
\hline
\end{tabular}

Number of families ${ }^{\mathrm{f}}$ living in household

1

2

$27 \quad 52.9$

$24 \quad 47.1$

Total number of people living in household

\begin{tabular}{lll}
$1-3$ & 15 & 29.4 \\
$4-6$ & 33 & 64.7 \\
$7+$ & 3 & 5.9 \\
\hline
\end{tabular}

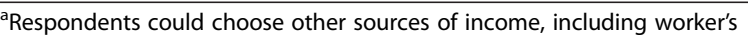
compensation/employment insurance, pension/senior's benefits or any other source (e.g., alimony, child tax benefits, etc.), however all respondents without a main income source from salary/wages chose social assistance.

${ }^{b}$ Based on participant responses to the Household Food Security Survey Module (HFSSM). The $n=49$ as two individuals chose not to respond to the HFSSM questionnaire.

Includes couples living alone or those with children $>18$ years.

${ }^{d}$ Includes lone parents living with at least one child $<18$ years.

e Includes unattached individuals not living with any children $<18$ years.

fA "family" was defined according to the Statistics Canada definition for Census Family [46] (Statistics Canada, 2012). 


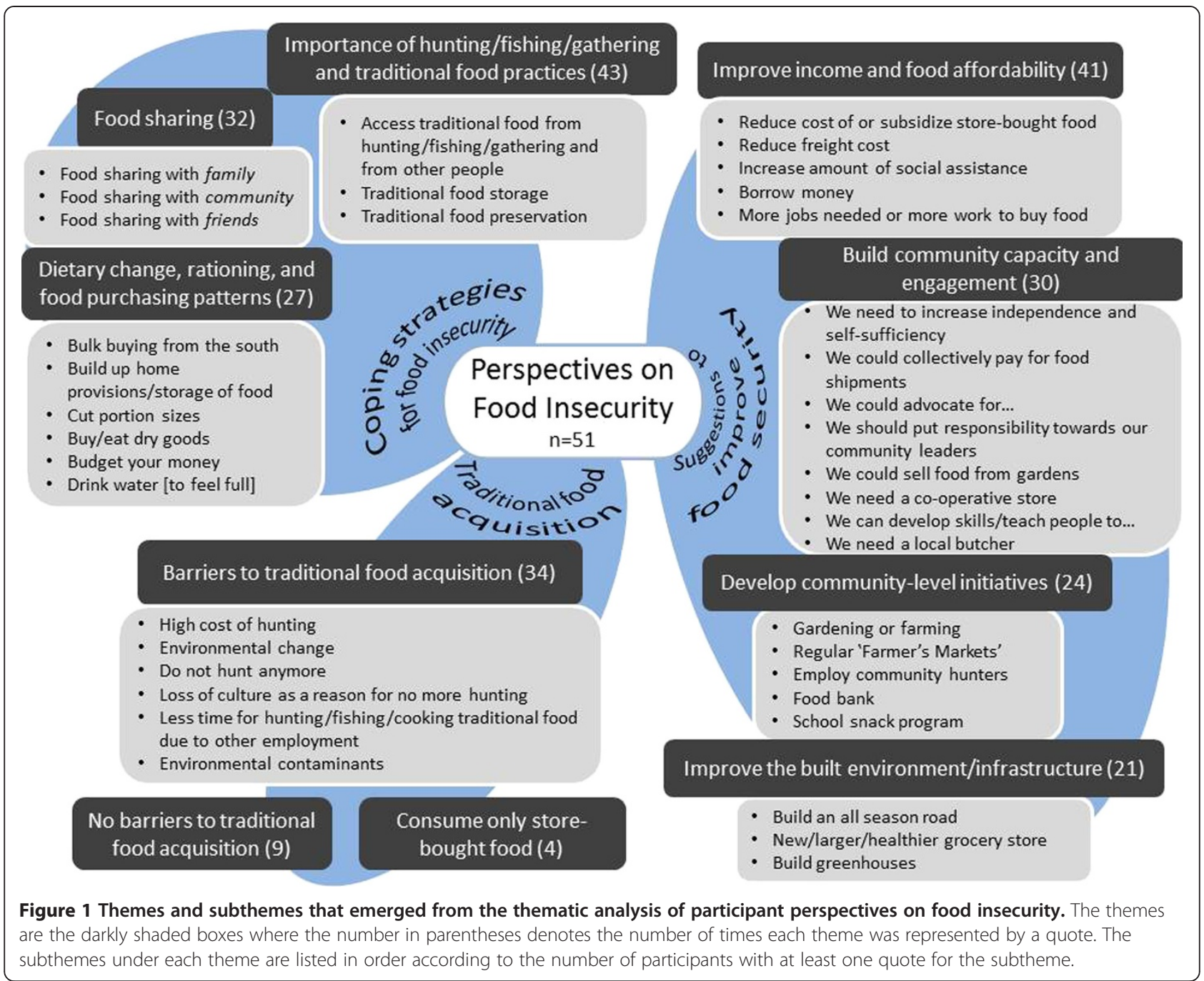

fell into the three question categories: traditional food acquisition; coping strategies for food insecurity; and suggestions to improve food security. For the remaining Results section, the paragraph headings are the themes. The full list of themes and subthemes are depicted in Figure 1.

\section{"Can you tell me about traditional foods and your household" \\ Barriers to traditional food acquisition}

When describing traditional food acquisition for their household, the majority of participants reported various barriers that prevented them from acquiring traditional food on a regular basis despite their desire to eat game meats more often. The two main barriers reported were the high cost of hunting and environmental change affecting their ability to hunt in specific areas and during specific times. The high costs were attributed primarily to the cost of fuel to travel to hunting sites and the financial means to own hunting equipment. Hunting equipment included vehicles for transportation, guns, and ammunition. A number of participants pointed out that even if money was spent to go out hunting, there was no guarantee that the hunt would be successful.

"It costs money to go hunting - gas, snow machine, and you need that money for everything else because everything is expensive." (Interview 4, female)

"Gas is expensive...\$1.85 a litre. But you can spend all the money to go out hunting and come back with nothing. So you've spent your money, but still have no food." (Interview 25, male)

"Still go hunting, geese, moose, caribou but the seasons are changing and it gets harder to get wild food. For spring hunting - geese fly at odd times now. In April it is still too cold, snow and sometimes it gets too warm and snow melts too fast. Geese won't land where there is no snow. I guess we have 
to change our hunting season [May and June] and go hunting at the Bay instead of the muskeg [swamp]. We try to get 12 geese at least and cook one per month." (Interview 17, male)

Other categories of barriers mentioned included the loss of culture as a reason for no more hunting; less [personal] time for hunting, fishing and cooking traditional food due to employment, and concern about environmental contaminants in hunted food.

\section{No barriers to traditional food acquisition}

A few participants did express that they thought there were no barriers to traditional food acquisition. However most of these people also admitted that they did not hunt, did not prefer game meat, or consumed only store-bought food.

\section{“How do you adapt if there doesn't seem to be enough food for your household" Importance of hunting/fishing/gathering and traditional food practices}

This importance of traditional food acquisition and traditional food practices was a prevalent discussion topic throughout the interviews and was the predominant theme across all three of the interview questions. In addition to describing their access of traditional food from hunting, fishing, and gathering for themselves, the participants also mentioned accessing food from other people and the importance of food practices such as storing and preserving traditional food for future consumption.

"As for me, I don't really eat traditional food only when family member gives me wild meat. Would be nice to eat traditional food every supper." (Interview 46, female)

\section{Food sharing}

When asked how they adapt when there wasn't enough food, the majority of participants mentioned food sharing. Food sharing with family was the most common, followed by food shared between community members and then food shared with friends. Food sharing with family included immediate family as well as relatives, even if the relatives lived in another community. Food sharing was seen as a normal part of daily life and occurred more often during hunting seasons when game meat was made available by hunters. Most of the participants described that the food shared was traditional game meats.

"We have get-togethers as family and we go to another family house and we share what we have in our homes and the other family does as well." (Interview 29, male)

"Our parents have a lot of wild meat and share with our family." (Interview 19, female)
"One way is to give food if other families can't afford to buy what they run out of." (Interview 45, female)

Dietary change, rationing, and food purchasing patterns Participants explained how they would change their eating and food purchasing patterns in times where they didn't have enough food or when they couldn't afford to purchase certain foods. They described how they bought food in bulk from the south and stocked up their provisions of nonperishable food when the winter road was usable. Some mentioned reducing portion sizes and changing their consumption patterns. For example, buying dry goods like rice and pasta which were cheaper to purchase.

"We buy more in Moosonee during the winter months. Buy foods such as macaroni, rice, other dry food."

(Interview 2, male)

"What do you think can be done to make it easier for people in Fort Albany to get enough (healthy) food" Improve income and food affordability

When participants were asked to suggest ways to make it easier for community members to get enough food, the majority pointed to the high prices of food at the local store and the low incomes of community residents. They thought that the store food should be reduced in price to become more affordable and that freight costs for shipping food should be decreased. Increasing income by increasing the amount of social assistance (welfare) payments or having more employment opportunities were also mentioned.

"Lower cost of food would be nice so all people can afford, especially welfare recipients." (Interview 5, male)

\section{Building community capacity and engagement}

Many participants discussed the importance of increasing independence and self-sufficiency so that they didn't have to rely on food transported from the south. They wanted to advocate for food security initiatives and put some of the responsibility for improving food security towards community leaders. For example, the Band and Band council were frequently mentioned and were viewed to be in a position to make positive changes towards increasing food availability and affordability. Many participants said "the Band should do this...". The participants used terms that indicated a collective movement whereby community members could work together towards solutions. For example, many respondents used the words "we could..." or "we should..." or "we need...".

"As for the last part of the question, one method is to move back in the upper bush land (upriver) and not depend on the white society. But...we, the First Nations 
in the communities have already accepted everything from the start...like the signing of the treaty or letting our kids go in the residential school to get educated... we need to be independent and start doing things for ourselves." (Interview 52, female)

"[There should be] scheduled hunting trips where gas and supplies are paid [by the Band] and traditional food/meat caught given to lower income families - salary for the hunter. This would provide jobs and feed the lower income groups. Lots of great hunters and trappers in this community - utilize them." (Interview 49, female)

\section{Community-level initiatives}

Participants also pointed out a number of communitylevel initiatives that they thought could improve food security. The most common community initiative suggested was related to gardening or farming. Community members were reminiscent about times in the past when they gardened or remembered when there used to be farming activity in the community.

"Start a garden. You could grow things like rhubarb for jam or pies. We used to have a garden and we grew potatoes. We used the potatoes at the goose camp. We know that you can grow things here."

(Interview 50, female)

Community members also were keen to continue and support the 'Farmer's Markets' that had been started by a few community food champions. The 'Farmer's Market' was an event initially held once every few months where food was purchased from a southern store and a plane was chartered to fly the food into the community. The food was then sold to community members at prices that covered the cost of the food and freight with no profit. These events were organized by a few people in the community who wanted to improve food access and affordability for community residents.

\section{"Okay, as for me I think they should hold more Farmer's Markets." (Interview 47, female)}

Another suggestion was to employ community hunters. This was seen as a way to increase the harvesting of traditional foods as well as income support for community members who were willing and keen to hunt, but might be unable to afford to hunt due to financial constraints.

"Get Band Council to get some hunters to go hunting for spring and fall. Supply the hunters with guns, shells, gas for their trip. Whatever game [meat] is killed, it should be shared within the community." (Interview 51, female)

\section{Improving the built environment/infrastructure}

Participants made recommendations for building physical structures to promote food security and these were categorized as improving the built environment or infrastructure. They primarily mentioned the building of an all-season road in the community. An all-season road could provide year-round access to southern stores and reduce the cost of transporting food into the community.

\section{"Maybe an all-season road will help to have more food in cupboards, like winter time." (Interview 37, male)}

Some participants also mentioned having a larger grocery store with more healthy food and that greenhouses should be built to grow local food in the community. The one main store in the community was regarded by residents as being too small for the size of Fort Albany, even when it was first built. In addition to housing groceries, the store also serves as the local bank and the only local business where residents can buy clothing, appliances, furniture, and electronics. Respondents expressed a desire to have better quality and more quantity of fresh fruits and vegetables as well as more fresh meat that had not been frozen. It is important to note that a small greenhouse was built at the community school over the summer and fall of 2010. The five by six meter greenhouse was partially funded through a university research grant as a case study of food security intervention strategies in the community. It was not clear from the interviews whether the respondents were motivated by the school greenhouse to suggest that more greenhouses be built or whether the idea of building greenhouses originated elsewhere.

\section{Discussion}

Over the past century, Aboriginal populations living in northern communities have become increasingly vulnerable to the transformation of local culture and society, including a significant shift from a primarily subsistence way of life [47]. They are no longer nomadic and do not experience extreme feast or famine situations as they had in the past; however in many communities the experience of food insecurity prevails. The introduction of storebought foods and reduction in traditional food acquisition has been a detrimental nutrition transition resulting in considerable changes to their health and well-being [11]. As northern and remote populations in Canada are continuing to be exposed to external stressors, such as environmental change; they become increasingly reliant on coping mechanisms to maintain food access $[14,19]$. Issues related to food security in Aboriginal populations that have not been studied in-depth include: how traditions of sharing and reciprocity of food contribute to food security; how families cope internally with food shortages; how 
individuals within families experience or cope with food shortages differently; how communities cope with widespread food insecurity; and what solutions or strategies have worked (or not worked) in the past and what new strategies are suggested by community members $[1,2,12]$. The goal of this study was to begin to explore some of these understudied issues from the perspectives of individuals living in a remote FN community. To our knowledge, this is the first study to examine coping strategies for food insecurity with a remote, subarctic FN population. The findings point to the continued importance of traditional food acquisition and food sharing as well as listening to proposed community solutions for food systems change.

\section{Traditional food acquisition and coping strategies for food insecurity}

Similar to findings from this study, the high cost of hunting and environmental change have been cited as barriers to traditional food acquisition and affecting food security for Aboriginal people living in Canada's north [15,19,48-53]. In this study, hunting, fishing, gathering of traditional food and traditional food practices (e.g., traditional food preservation and storage) were important ways for community members to cope with food shortages. Subsistence harvesting for Cree of the western and eastern James Bay region remains an integral part of the culture [54-59]. Outside of the clear nutritional value of wild food, the spring and fall harvesting periods constitute a cultural event which increases social and community cohesiveness. The extremely high cost of market food is prohibitive [60,61]. Thus, the contribution of wild food to the Cree diet must be preserved for both economic and cultural reasons [56]. The importance of traditional food for northern populations has been well documented [18,52,53]. Traditional food storage has become modernized with the use of freezers to store game meat for future consumption. It was not clear from the interviews whether the preservation of food, such as smoking or drying, has decreased with the increased use of freezers.

Food sharing was expressed by $63 \%$ of participants as a means of coping with food shortage. This important part of Aboriginal culture and traditions has been documented widely in the literature $[6,15,19,55,62-66]$ including food sharing by the James Bay Cree $[57,58]$. The First Nations Regional Health Survey [6] found that nearly nine of ten $(85.5 \%)$ respondents had traditional food shared with their household in the past year prior to the survey. Fort Albany residents felt that food sharing between family, community members, and friends was a key coping strategy when their household did not have enough food. In contrast to a few recent studies reporting that food sharing has been decreasing in northern Aboriginal communities $[14,19,66]$, the current study found that food sharing continues to be an important way for community members to adapt to food shortages and a weakening of food sharing was not mentioned during interviews. Other studies pointing to a decline in food sharing networks cite reasons including the high cost of hunting; an increasing number of households without a hunter; and stress on hunting yields due to environmental changes $[14,19,62,66]$. The high costs of hunting and environmental change were both subthemes that emerged as barriers to traditional food acquisition in Fort Albany.

Dietary change, such as consuming less expensive food like rice and pasta, and rationing of food intake are coping mechanisms for food insecurity that emerged from the current interviews and are commonly cited in the literature [67-70]. Less severe forms of food rationing include cutting portion sizes to more severe behaviours such as skipping meals completely [67,71]. Participants of this study even mentioned drinking water to feel full, which indicates the severity of food insecurity for some Fort Albany residents. Specific food purchasing patterns, such as buying in bulk from more southern stores and using this practice to build up home food provisions may be unique to remote communities with seasonal road access. After freeze-up when the winter road can be safely travelled is a time of year with a great flurry of community activity as people try to buy supplies that they otherwise have difficulty accessing due to reduced availability and cost at their local store.

\section{Suggestions to improve food security}

It must not be overlooked that the key determinant of food insecurity is poverty [72,73]. Income and food costs become more powerful determinants of food selection due to wide spread poverty and reliance on social assistance in many Aboriginal communities [2]. Suggestions to improve food security in Fort Albany reflect the reality of low incomes and high food costs in the community. However, it is positive that Fort Albany members are keen to start building community capacity and engagement and initiate community-level initiatives to improve their food security. Community-driven initiatives in FN communities tend to result in greater community buy-in and more successful outcomes.

Initiating and maintaining nonconventional agricultural initiatives have the potential for the community to increase self-sufficiency and reduce reliance on imported produce [74]. Likewise, hiring community hunters could reduce dependence on meat transported from the south and provide employment. While gardening and farming would require considerable commitment by community residents, it is already gaining momentum in the community and has benefitted from pilot-projects, including a provincially funded "Get Growing" community garden project [75] and a pilot agroforestry (local-substitution) project [74]. Community gardens have been suggested by other studies as 
a step towards greater food security and food sovereignty $[66,74]$. Harvester support programs that subsidize the cost of hunting, fishing, and trapping have been carried out in the Arctic [16,76] and subarctic [77] resulting in benefits at the community level.

In 2007 community food champions in Fort Albany began to organize a non-profit 'farmer's market' event every few months. A plane would be chartered to fly in fresh and healthy food to be sold at cost to local residents. This means the prices are at least $50 \%$ lower than the same foods sold at the local grocery store because there are no overhead costs. Fort Albany has now started to call their 'Farmer's Markets' an 'alternative market'. The concept of their alternative market has begun to receive attention from a broader audience, has grown into a bi-weekly event and is being supported by external agencies that are aiming to improve northern food systems [61]. Awareness by external groups of the alternative market increased after it was presented at a national food security conference in November 2012 [78,79]. While the alternative food market does not move the community food system towards greater self-sufficiency, it can help the community take more control over food pricing of transported foods and may lead to feeling empowered for food system change.

Building an all-season road into the community was suggested by numerous participants, but is a contentious issue. On one hand, having an all-season road would mean the ability to travel by truck to other neighbouring communities - and a year-round land connection to more southerly communities - where food costs are lower even taking into account the added cost of transportation for foods imported into the community. However year-round land access could also have negative consequences, such as the greater ease of transporting drugs and alcohol. Thompson and colleagues [80] found that fly-in communities in northern Manitoba generally had more severe and higher rates of food insecurity than those with road or train access.

The participants in this study spoke about the need to increase independence and self-sufficiency with respect to accessing adequate food. They are not alone with this plea as the indigenous food sovereignty movement has been gaining momentum in Canada and has been documented through the People's Food Policy project. They state that the "tribal values of giving, sharing and trading are at the heart of land care and food sovereignty" and that "the core of food sovereignty is reclaiming public decisionmaking power in the food system." [81]. Fort Albany residents did not use the exact term food sovereignty during their interview dialogue, but food sovereignty was, in essence, what they were describing; they expressed a desire and suggested strategies to enhance their independence, self-sufficiency and acquisition of new skills, in addition to advocating for better food security. Food security is a precondition for, and outcome of, food sovereignty. The goal is to achieve food security concurrently with food sovereignty.

The strengths of this research include the large sample of community members that participated in the interviews and the willingness of the respondents in describing their experience of food insecurity despite the sensitivity of the topic. Participants were likely more willing to discuss their perceptions of being food insecure because of their comfort level and rapport with the local community research assistant who conducted the interviews. There were two main limitations of this study: the inability to audiorecord the interviews and the generalizability of the results. First of all, although it was deemed inappropriate by the CAC to audio-record the interviews, audio-recording would have allowed the interviewer to focus all of his attention on questioning and listening during the conversation as well as capturing elements of tone and emphasis made by the participants. However, one advantage of the absence of a tape recorder is that it may have led to the relaxed nature of the interviews. Secondly, the findings in this study are not generalizable to individuals living in contexts that vary greatly in terms of food accessibility and availability. For example, those living off-reserve and in more accessible geographic locations where store bought food is considerably less expensive and where traditional food practices are not an integral and important part of the food system.

\section{Conclusions}

Aboriginal people in Canada like the remote community of Fort Albany experience staggering rates of food insecurity and it continues to be an urgent and pervasive public health issue. Findings from this study point to the continued importance of traditional food acquisition and food sharing as well as listening to proposed community solutions for food systems change. These data highlight that traditional and store-bought food are both part of the strategies and solutions participants suggested for coping with food insecurity. The findings can be used to inform assessment and program planning activities and to advocate for policies at the local, provincial and federal levels to strengthen community food security, specifically in remote Aboriginal communities. Public health policies to improve food security for FN populations are urgently needed. While short and medium term strategies (e.g., greater employment and building community gardens and greenhouses) are important for initiating food systems change, long term sustainable food systems require policy strategies and instruments to be effective in building and strengthening food security and community capacity. Thompson and colleagues $[80,82]$ have suggested that community economic development and supporting sustainable 
livelihoods through local food production and local food networks can improve food security and re-establish food sovereignty in northern FN communities.

Fort Albany was at the forefront of the Food Secure Canada conference in 2012 when the newly elected Chief of Fort Albany received a standing ovation for his emotional speech on food sovereignty in remote communities [79]. Community members in Fort Albany are speaking up about the need for food systems change, and it appears that their local leaders are listening and supporting their mission. It's time for the provincial and federal governments in Canada to pay attention and to work with remote communities towards greater food security and to support a vision for food sovereignty.

\section{Abbreviations \\ FN: First Nations; CAC: Community Advisory Committee; HFSSM: Household} Food Security Survey Module.

\section{Competing interests}

The authors declare that they have no competing interests.

\section{Authors' contributions}

$\mathrm{KS}, \mathrm{RH}$ and LT designed and coordinated the study. KS conducted the qualitative analysis and wrote the manuscript. ED assisted with analysis. All authors read and approved the final manuscript.

\section{Acknowledgements}

The authors are grateful to all the community members that participated, the Community Advisory Committee, the community research assistant who collected the data and for the support of Fort Albany First Nation. The lead author was supported by a Doctoral Research Award from the Canadian Institutes of Health Research and an Ontario Graduate Scholarship. This study was funded by the Canadian Institutes of Health Research, the Social Science and Humanities Research Council of Canada and the Canadian Foundation for Dietetic Research.

\section{Author details}

${ }^{1}$ School of Public Health and Health Systems, University of Waterloo, 200 University Avenue West, Waterloo, ON N2L 3G1, Canada. ${ }^{2}$ Department of Geography and Environmental Management, University of Waterloo, 200 University Avenue West, Waterloo, ON N2L 3G1, Canada. ${ }^{3}$ Department of Environment and Resource Studies, University of Waterloo, 200 University Avenue West, Waterloo, ON N2L 3G1, Canada.

\section{Received: 26 November 2012 Accepted: 27 April 2013}

\section{Published: 2 May 2013}

\section{References}

1. Power EM: Conceptualizing food security for Aboriginal people in Canada. Can J Public Health 2008, 99:95-97.

2. Willows ND: Determinants of healthy eating in Aboriginal Peoples in Canada. Can J Public Health 2005, 96(Suppl):32-41.

3. Che J, Chen J: Food insecurity in Canadian households. Health Rep 2001, 12:11-22.

4. Health Canada: Canadian Community Health Survey, Cycle 2.2, Nutrition: Incomerelated household food security in Canada. 2004. [http://www.hc-sc.gc.ca/fn-an/ alt_formats/hpfb-dgpsa/pdf/surveill/income_food_sec-sec_alim_e.pdf] 2007.

5. Willows ND, Veugelers P, Raine K, Kuhle S: Prevalence and sociodemographic risk factors related to household food security in Aboriginal peoples in Canada. Public Health Nutr 2008, 12:1150-1156.

6. The First Nations Information Governance Centre: First Nations Regional Health Survey (RHS) Phase 2 (2008/10) National Report on Adults, Youth and Children Living in First Nations Communities. Ottawa: The First Nations Information Governance Centre; 2012.

7. Rosol R, Huet C, Wood M, Lennie C, Osborne G, Egeland GM: Prevalence of affirmative responses to questions of food insecurity: International Polar
Year Inuit Health Survey, 2007-2008. Int J Circumpolar Health 2011, 70:488-497.

8. Agriculture and Agri-Food Canada: Canada's fourth progress report on food security. 2006 [http://www.agr.gc.ca/misb/fsec-seca/pdf/report-rapport_4_e.pdf].

9. Dietitians of Canada: Individual and household food insecurity in Canada: positions of Dietitians of Canada. 2005 [http://www.dietitians.ca/

Downloadable-Content/Public/householdfoodsec-position-paper.aspx].

10. Dietitians of Canada: Community food security: position of Dietitians of Canada. 2007 [http://www.dietitians.ca/Downloadable-Content/Public/cfsposition-paper.aspx].

11. Kuhnlein HV, Receveur O: Dietary change and traditional food systems of Indigenous Peoples. Ann Rev Nutr 1996, 16:417-442.

12. Power E: Food security for First Nations and Inuit in Canada background paper. Health Canada: Prepared for the First Nations and Inuit Health Branch; 2007.

13. Willows ND, Iserhoff R, Napash L, Leclerc L, Verrall T: Anxiety about food supply in Cree women with infants in Quebec. Int $J$ Circumpolar Health 2005, 64:55-64.

14. Beaumier MC, Ford JD: Food insecurity among Inuit women exacerbated by socioeconomic stresses and climate change. Can J Public Health 2010, 101:196-201.

15. Chan HM, Fediuk K, Hamilton S, Rostas L, Caughey A, Kuhnlein H, Egeland G, Loring E: Food security in Nunavut, Canada: barriers and recommendations. Int J Circumpolar Health 2006, 65:416-431.

16. Duhaime G, Godmaire A: The conditions of sustainable food security: an integrated conceptual framework. In Sustainable Food Security in the Arctic: State of Knowledge. Edited by Duhaime G. Edmonton: Canadian Circumpolar Institute, University of Alberta, in cooperation with the Groupe d'études inuit et circumpolaires, Laval University; 2002:15-45.

17. Egeland GM, Pace A, Cao Z, Sobol I: Food insecurity among Inuit preschoolers: Nunavut Inuit Child Health Survey, 2007-2008. CMAJ 2010, 182:243-248.

18. Egeland GM, Johnson-Down L, Cao ZR, Shiekh N, Weiler H: Food insecurity and nutrition transition combine to affect nutrient intakes in Canadian Arctic communities. J Nutr 2011, 141:1746-1753.

19. Ford JD, Beaumier M: Feeding the family during times of stress: experience and determinants of food insecurity in an Inuit community. Geogr J 2011, 177:44-61.

20. Ford JD, Lardeau M-P, Vanderbilt W: The characteristics and experience of community food program users in arctic Canada: a case study from Iqualuit, Nunavut. BMC Public Health 2012, 12:464. online.

21. Huet C, Rosol R, Egeland GM: The prevalence of food insecurity is high and the diet quality poor in Inuit communities. J Nutr 2012, 142:541-547.

22. Lambden J, Receveur O, Marshall J, Kuhnlein HV: Traditional and market food access in Arctic Canada is affected by economic factors. Int J Circumpolar Health 2006, 65:331-340.

23. Lardeau M-P, Healey G, Ford J: The use of Photovoice to document and characterize the food security of users of community food programs in Iqaluit, Nunavut. Rural Remote Health 2011, 11:1680. online.

24. Skinner K, Hanning RM, Tsuji LJS: Prevalence and severity of household food insecurity of First Nations people living in an on-reserve, subarctic community within the Mushkegowuk Territory. Public Health Nutr. in press.

25. Skinner $\mathrm{K}$, Hanning RM, Sutherland $\mathrm{C}$, Edwards-Wheesk R, Tsuji LJ: Using a SWOT analysis to inform healthy eating and physical activity strategies for a remote First Nations community in Canada. Am J Health Promot 2012, 26:e159-e170.

26. Skinner K, Hanning RM, Metatawabin J, Martin ID, Tsuji LJ: Impact of a school snack program on the dietary intake of grade six to ten First Nations students living in a remote community in northern Ontario, Canada. Rural Remote Health 2012, 12:2122. online.

27. Skinner K, Hanning RM, Tsuji LSS: Barriers and supports for healthy eating and physical activity for First Nation youths in northern Canada. Int J Circumpolar Health 2006, 65:148-161.

28. Tsuji LS, Nieboer E, Karagatzides JD, Hanning RM, Katapatuk B: Lead shot contamination in edible portions of game birds and its dietary implications. Ecosystem Health 1999, 5:183-192.

29. Getty GA: The journey between Western and Indigenous research paradigms. J Transcult Nurs 2010, 21:5-10.

30. Lambden J, Receveur O, Kuhnlein HV: Traditional food attributes must be included in studies of food security in the Canadian Arctic. Int $\rfloor$ Circumpolar Health 2007, 66:308-319. 
31. Cohen B: Community food security assessment toolkit. 2002 [http://www.ers. usda.gov/publications/efan02013/efan02013.pdf].

32. Noaks L, Wincup E: Criminological research - understanding qualitative methods. London: Sage Publications; 2004:80.

33. Fontana A, Frey $\mathrm{JH}$ : The interview: from structured questions to negotiated text. In Handbook of Qualitative Research. 2nd edition. Edited by Denzin NK, Lincoln YS. Thousand Oaks: Sage; 2000:645-672.

34. Kirby $A M$, Lévesque $L$, Wabano V, Robinson-Wilson J: Perceived community environment and physical activity involvement in a northern-rural Aboriginal community. Int J Beh Nutr Phys Act 2007, 4:63. online.

35. Boyatzis RE: Transforming qualitative information: thematic analysis and code development. Thousand Oaks: Sage Publications; 1998.

36. Patton MQ: Utilization-focused evaluation: the new century text. 3rd edition. Thousand Oaks: Sage Publications; 1997

37. Braun V, Clarke V: Using thematic analysis in psychology. Qualitative Res Psychol 2006, 3:77-101.

38. Charmaz K: Constructing Grounded Theory: A Practical Guide through Qualitative Analysis. Thousand Oaks: Sage Publications; 2006

39. Strauss A, Corbin J: Basics of Qualitative Research: Techniques and Procedures for Developing Grounded Theory. Thousand Oaks: Sage Publications; 1990.

40. Lofland J, Lofland LH: Chapter 9: developing analysis. In Analyzing Social Settings: a Guide to Qualitative Observation and Analysis. Belmont: Wadsworth Publishing; 1995:182-203.

41. Hruschka DJ, Schwartz D, St. John DC, Picone-Decaro E, Jenkins RA, Carey JW: Reliability in coding open-ended data: lessons from HIV behavioral research. Field Methods 2004, 16:307-331.

42. Patton MQ: Chapter 9: Enhancing the quality and credibility of qualitative analysis. In Qualitative Evaluation \& Research Methods. Newbery Park: Sage Publications; 2002:541-588.

43. Desjardins E: Place and Food: a Relational Analysis of Personal Food Environments, Meanings of Place and Diet Quality. PhD thesis. Wilfred Laurier University: Department of Geography and Environmental Studies; 2010.

44. McCullum C, Desjardins E, Kraak VI, Ladipo P, Costello H: Evidence-based strategies to build community food security. J Am Diet Assoc 2005, 105:278-283.

45. Lincoln YS, Guba EG: Naturalistic Inquiry. Newbury Park: Sage Publications; 1985.

46. Statistics Canada: Concept: census family. Ottawa: Statistics Canada; 2012 [http://www.statcan.gc.ca/concepts/definitions/cfamily-rfamille-eng.htm]

47. Sydneysmith R, Andrachuk M, Smit B, Hovel GK: Chapter 7: Vulnerability and adaptive capacity in Arctic communities. In Adaptive Capacity and Environmental Governance. Edited by Armitage D, Plummer R. London: Springer; 2010:133-156.

48. Furgal C, Seguin J: Climate change, health, and vulnerability in Canadian northern Aboriginal communities. Environ Health Perspect 2006, 114:1964-1970.

49. Guyot M, Dickson C, Paci C, Furgal C, Chan HM: Local observations of climate change and impacts on traditional food security in two northern Aboriginal communities. Int J Circumpolar Health 2006, 65:403-415.

50. Lemelin H, Matthews D, Mattina C, McIntyre N, Johnston M, Koster R: Climate change, well-being, and resilience in the Weenusk First Nation at Peawanuck: The Moccasin Telegraph goes global. Rural Remote Health 2010, 10:1333.

51. Lougheed $T$ : The changing landscape of Arctic traditional food. Environ Health Perspect 2010, 118:386-393.

52. Nancarrow TL, Chan HM: Observations of environmental changes on potential dietary impacts in two communities in Nunavut, Canada. Rural Remote Health 2010, 10:1370. Online.

53. Schuster RC, Wein EE, Dickson C, Chan HM: Importance of traditional foods for the food security of two First Nations communities in the Yukon, Canada. Int J Circumpolar Health 2011, 70:286-300.

54. Berkes F, George PJ, Preston RJ, Hughes A, Turner J, Cummins BD: Wildlife harvesting and sustainable regional native economy in the Hudson and James Bay Lowland, Ontario. Arctic 1994, 47:350-360.

55. Delormier T: Traditional food of the James Bay Cree of Quebec. Ottawa, ON: Final Report to Health and Welfare Canada; 1993.

56. Tsuji LJS: Mandatory use of non-toxic shotshell for harvesting of migratory game birds in Canada: cultural and economic concerns. Can J Native Stud 1998, 18:19-36.

57. Tsuji LJS, Nieboer E: A question of sustainability in Cree harvesting practices: the seasons, technological and cultural changes in the western James Bay region of northern Ontario, Canada. Can J Native Stud 1999, 19:169-192.
58. Tsuji LU, Manson H, Wainman BC, Vanspronsen EP, Shecapio-Blacksmith J, Rabbitskin T: Identifying potential receptors and routes of contaminant exposure in the traditional territory of the Ouje-Bougoumou Cree: Land use and a geographical information system. Environ Monit Assess 2007 127:293-306.

59. Tsuji LJS, Edwards E, Ashamock M, Stephens A, Hunter J, Edwards R, Edwards G, Martin ID, LeBlanc A, Dumas P: Spring-harvested game birds from the western James Region of northern Ontario, Canada: organochlorine concentrations in breast tissues. Ottawa, ON: Health Canada Report; 2006.

60. Gates A, Hanning RM, Gates M, Skinner K, Tsuji LS: Vegetable and fruit intakes of on-reserve First Nations schoolchildren compared to Canadian averages and current recommendations. Int J Environ Res Public Health 2012, 9:1379-1397.

61. LeBlanc J, Veeraraghavan G: Food program a hit in Fort Albany. Spring: In The NAN Advocate; 2012

62. Ford JD: Vulnerability of Inuit food systems to food insecurity as a consequence of climate change: a case study from Igloolik, Nunavut. Regional Environmental Change 2009, 9:83-100.

63. Gombay N: From subsistence to commercial fishing in Northern Canada: the experience of an Inuk entrepreneur. British Food J 2007, 108:502-521.

64. Kaplan H, Gurven M: The natural history of human food sharing and cooperation: a review and a new multi-individual approach in the negotiation of norms, version 1.3. Albuquerque, NM: University of New Mexico; 2001.

65. Robidoux MA, Haman F, Sethna C: The relationship of the burbot (Lota lota L.) to the reintroduction of off-the-land foods in the Sandy Lake First Nation Community. Biodemography Soc Biol 2009, 55:12-29.

66. Socha T, Zahaf M, Chambers L, Abraham R, Fiddler T: Food security in a northern First Nations community: an exploratory study on food availability and accessibility. J Aboriginal Health 2012, 8:5-14.

67. Maxwell D, Ahiadeke C, Levin C, Amar-Klemesu M, Zakariah A, Lamptey GM: Alternative food security indicators - revisiting the frequency and severity of coping strategies. Food Policy 1999, 24:411-429.

68. Maxwell D, Caldwell R: The coping strategies index: field methods manual. 2nd edition. 2008 [http://documents.wfp.org/stellent/groups/public/ documents/manual_guide_proced/wfp211058.pdf].

69. Norhasmah S, Zalilah MS, Mohd Nasir MT, Kandiah M, Asnarulkhadi AS: A qualitative study on coping strategies among women from food insecurity households in Selangor and Negeri Sembilan. Mal J Nutr 2010, 16:39-54.

70. Shariff ZM, Kohr GL: Household food insecurity and coping strategies in a poor rural community in Malaysia. Nutr Res Pract 2008, 2:26-34.

71. Tarasuk V: Discussion paper on household and individual food insecurity. Health Canada; 2001 [http://www.hc-sc.gc.ca/fn-an/nutrition/pol/ food_sec_entire-sec_aliments_entier-eng.php].

72. McIntyre L: Food security: more than a determinant of health. Policy Options 2003 [http://www.irpp.org/po/archive/mar03/mcintyre.pdf].

73. Rose D: Economic determinants and dietary consequences of food insecurity in the United States. J Nutr 1999, 129(Suppl):517-520.

74. Spiegelaar N: Agroforestry community gardens as a sustainable importsubstitution strategy for enhancing food security in remote First Nations of subarctic Ontario, Canada. MES thesis. University of Waterloo, Department of Environment and Resource Studies; 2011.

75. LeBlanc J: Get Growing program. In Nishnawbe Aski Nation Annual Report 2011-2012. Thunder Bay, ON: Nishnawbe Aski Nation; 2012

76. Government of Nunavut: A consultation-based review of the harvester support programs of the Government of Nunavut and Nunavut Tunngavik Inc. 2008 [http://www.tunngavik.com/documents/publications/2008-08-11-Review-ofHarvester-Support-Programs-Final-Report-ENG.pdf].

77. No author: An Act respecting the support program for Inuit beneficiaries of the James Bay and Northern Québec agreement for their hunting, fishing and trapping activities, RSQ, c P-30.2. 2006 [http://canlii.ca/t/hbqv].

78. Food Secure Canada: Preliminary program for Powering up Food for the Future: Food Secure Canada's 7th National Assembly. 2012 [http:// foodsecurecanada.org/sites/foodsecurecanada.org/files/FSC EdmontonProgram-web.pdf].

79. Food Secure Canada Conference 'PoweringUP-Food for the Future!'. 2012 [http://storify.com/milzofsmilz/pwrup2012-food-secure-canada-conferencepoweringu].

80. Thompson S, Kamal AG, Alam MA, Wiebe J: Community development to feed the family in northern Manitoban communities: evaluating food activities based on their food sovereignty, food security, and sustainable livelihood outcomes. Canadian J Nonprofit Soc Econ Res 2012, 3(2):43-66. 2012 
81. Food Secure Canada: Resetting the table: a people's food policy for Canada. 2011 [http://foodsecurecanada.org/sites/foodsecurecanada.org/files/FSCresetting2012-8half11-lowres-EN.pdf].

82. Thompson S, Gulrukh A, Ballard M, Beardy B, Islam D, Lozeznik V, Wong K: Is community economic development putting healthy food in the table? Food sovereignty in northern Manitoba's Aboriginal communities. J Aboriginal Econ Dev 2011, 7(2):14-29.

doi:10.1186/1471-2458-13-427

Cite this article as: Skinner et al: Giving voice to food insecurity in a remote indigenous community in subarctic Ontario, Canada: traditional ways, ways to cope, ways forward. BMC Public Health 2013 13:427.

\section{Submit your next manuscript to BioMed Central and take full advantage of:}

- Convenient online submission

- Thorough peer review

- No space constraints or color figure charges

- Immediate publication on acceptance

- Inclusion in PubMed, CAS, Scopus and Google Scholar

- Research which is freely available for redistribution 